\title{
Low serum testosterone is a predictor of high-grade disease in patients with prostate cancer
}

\author{
George A. M. Lins de Albuquerque ${ }^{1 *}$, Giulano B. Guglelmetti², João Arthur B. A. Barbosa ${ }^{3}$, José Pontes Jr. ${ }^{2}$, \\ Arnaldo J. C. Fazoli², Maurício D. Cordeiro², Rafael F. Coelho², Paulo Afonso de Carvalho², Fábio P. Gallucci², \\ Guilherme P. Padovani ${ }^{2}$, Rubens Park ${ }^{2}$, José Cury ${ }^{4}$, Henrique Nonemacher ${ }^{5}$, Miguel Srougi ${ }^{6}$, William C. Nahas ${ }^{7}$ \\ ${ }^{1}$ Assistant Physician, Urology Service, Hospital Universitário Getúlio Vargas/Universidade Federal do Amazonas (HUGV/UFAM), and Assistant Physician, Urology Service, Fundação Centro de Controle \\ em Oncologia do Estado do Amazonas (FCECON), Manaus, AM, Brazil \\ ${ }^{2}$ Assistant Physician, Urology Service, Instituto do Câncer do Estado de São Paulo (Icesp), Hospital das Clínicas, Faculdade de Medicina da Universidade de São Paulo (HC-FMUSP), São Paulo, SP, Brazil \\ ${ }^{3}$ Urology Resident Physcian, HC-FMUSP, São Paulo, SP, Brazil \\ ${ }^{4} \mathrm{MD}$ Urologist, HC-FMUSP. Head of the Sexual Medicine Group, São Paulo, SP, Brazil \\ ${ }^{5}$ Fellow in Urologic Oncology, Icesp, HC-FMUSP, São Paulo, SP, Brazil \\ ${ }^{6}$ Full Professor of Urology, FMUSP, São Paulo, SP, Brazil \\ ${ }^{7}$ Full Professor of Urology, FMUSP, and Head of the Urologic Oncology Group at Icesp, São Paulo, SP, Brazi
}

Study conducted at Division of Urology, Instituto do Câncer do Estado de São Paulo, Faculdade de Medicina, Universidade de São Paulo (Icesp/ HC-FMUSP), São Paulo, SP, Brazil

Article received: $7 / 3 / 2017$ Accepted for publication: 7/21/2017

*Correspondence: Address: Av. Dr. Arnaldo, 251 Cerqueira César

São Paulo, SP - Brazil Postal code: 01246-000 george_lins@hotmail.com

http://dx.doi.org/10.1590/1806-9282.63.08.704

\section{SUMMARY}

Objective: To evaluate the relation between serum total testosterone (TT) and prostate cancer $(\mathrm{PCa})$ grade and the effect of race and demographic characteristics on such association.

Method: We analyzed 695 patients undergoing radical prostatectomy (RP), of whom 423 had serum TT collected. Patients were classified as having hypogonadism or eugonadism based on two thresholds of testosterone: threshold $1(300 \mathrm{ng} / \mathrm{dL})$ and threshold $2(250 \mathrm{ng} / \mathrm{dL})$. We evaluated the relation between TT levels and a Gleason score (GS) $\geq 7$ in RP specimens. Outcomes were evaluated using univariate and multivariate analyses, accounting for race and other demographic predictors. Results: Out of 423 patients, $37.8 \%$ had hypogonadism based on the threshold 1 and $23.9 \%$ based on the threshold 2. Patients with hypogonadism, in both thresholds, had a higher chance of $G S \geq 7$ (OR 1.79, $\mathrm{p}=0.02$ and OR 2.08, $\mathrm{p}=0.012$, respectively). In the multivariate analysis, adjusted for age, TT, body mass index (BMI) and race, low TT $(\mathrm{p}=0.023)$ and age $(\mathrm{p}=0.002)$ were found to be independent risk factors for $\mathrm{GS} \geq 7$. Among Black individuals, low serum TT was a stronger predictor of high-grade disease compared to White men ( $\mathrm{p}=0.02)$.

Conclusion: Hypogonadism is independently associated to higher GS in localized $\mathrm{PCa}$. The effect of this association is significantly more pronounced among Black men and could partly explain aggressive characteristics of PCa found in this race.

Keywords: prostate cancer, hypogonadism, testosterone.

\section{INTRODUCTION}

Prostate cancer (PCa) is the second most common cancer in males in western countries ${ }^{1}$ and the known risk factors are age, diet, race and family history. ${ }^{2}$ The relationship between PCa and testosterone was first described by Huggins over 70 years ago ${ }^{3}$ and has become controversial as accumulated evidence demonstrating potentially opposing effects of androgens on cancer. ${ }^{4-6}$ Testosterone is vital for normal development and growth of the prostate and, conversely, androgen deprivation therapy in metastatic PCa significantly decreases symptoms and disease progres- sion. On these grounds, high levels of testosterone are believed to increase the risk of developing PCa. However, epidemiological investigations failed to demonstrate such association. ${ }^{7}$ Morgentaler et al. ${ }^{8}$ reported a high prevalence of PCa among asymptomatic men with low levels of total and free testosterone. This was the first study to show that low testosterone levels do not provide protection to the development of PCa.

Attention has also been drawn to the effect of testosterone on the histological grade of PCa, with a number of studies suggesting that low serum total testoster- 
one (TT) may be associated with higher-grade disease. Park et al. ${ }^{9}$ retrospectively evaluated 681 patients undergoing prostate biopsy and found an independent association between laboratorial hypogonadism, defined as TT below $300 \mathrm{ng} / \mathrm{dL}$, and high-grade PCa at biopsy. Studies performed in patients presenting PCa with clinically localized disease treated with radical prostatectomy (RP) also demonstrated that low levels of TT preoperatively were associated with more aggressive disease based on higher pathological stage, positive surgical margins and Gleason score (GS). ${ }^{10,11}$ However, an independent association has not been uniformly demonstrated in all investigations. ${ }^{12,13}$ Most studies have been performed in Caucasian and Asian populations, yet without specifying the effect of demographic characteristics on the association between TT and higher-grade PCa. Possible explanations for the inconsistency between existing studies include demographic variability, variable cutoffs for hypogonadism and biased samples.

The purpose of our study was to evaluate if serum TT levels are associated with higher-grade PCa and to evaluate the effect of race and other demographic predictors in this association in a multiethnic population.

\section{Method}

Institutional Review Board approval was obtained prior to the beginning of investigations. We retrospectively reviewed charts of 695 patients undergoing RP from January 2010 to December 2011 at a single tertiary care center. Patients who had TT levels measured from 6 months to 1 day before the surgery totalized 423 and were included for analysis. If more than one TT measurement was performed, levels obtained the closest to the surgery were used. TT measurement was performed at the discretion of the attending physician; TT results obtained more than 6 months prior to surgery were not included, which caused a number of subjects to be excluded from analysis.

We studied the association between preoperative serum TT levels and the pathological outcomes of the surgical specimens. Only patients with clinically localized disease who underwent RP as treatment were included. Salvage radical prostatectomies were excluded from analysis.

\section{Statistical analysis}

Patients were divided into groups of normal and low testosterone based on 2 threshold levels for TT: threshold $1(<300 \mathrm{ng} / \mathrm{dL}$ vs. $\geq 300 \mathrm{ng} / \mathrm{dL})$ and threshold $2(<250$ $\mathrm{ng} / \mathrm{dL}$ vs. $\geq 250 \mathrm{ng} / \mathrm{dL}$ ). High-grade PCa was considered as a Gleason score $\geq 7$.
Fisher's exact test was used to evaluate associations between binomial variables. To compare means between groups, we used the t-Student test for independent samples with normal distribution or the nonparametric Kruskal-Wallis when appropriate. We evaluated the relation between TT and pathological findings such as: pathological stage, GS and positive lymph nodes. Multivariate analysis considering age, body mass index (BMI), TT and race was performed for the outcomes of interest. A linear regression model was used to evaluate the relationship between PSA and testosterone levels. All statistical analyses were performed using SPSS 20.0 (IBM Software).

\section{Results}

Table 1 shows the clinical preoperative data for age, BMI, testosterone levels and PSA. Table 2 depicts the pathological characteristics of patients according to race, age-adjusted Charlson comorbidity index, prostate-specific antigen (PSA), TT levels (threshold 1 and threshold 2) and pathologic evaluation of RP specimens. Of $423 \mathrm{pa}-$ tients, $37.8 \%$ had hypogonadism based on threshold 1 and $23.9 \%$ based on threshold 2 .

On univariate analysis, patients with hypogonadism had higher prevalence of GS $\geq 7$ in RP specimens for both thresholds. There was no difference between groups in terms of rates of lymph node metastases and pathological stage (Table 3 and Table 4). Considering the levels of TT as a continuous variable, we observed that decreasing TT levels were associated with a progressive increase in the risk of having GS $\geq 7$ ( $p$-value $=0.0157$ ). Levels of TT did not correlate with levels of PSA on a linear regression fashion (R square goodness-of-fit 0.0002; $\mathrm{p}=0.77$ ).

On multivariate analysis, adjusted for age, TT levels, BMI and race, only low TT levels $(\mathrm{p}$-value $=0.0231)$ and advanced age $(\mathrm{p}$-value $=0.0018)$ were independent risk factors for high-grade disease (Gleason $\geq 7$ ).

In our data, Black men had a higher incidence of hypogonadism compared to Caucasians ( $\mathrm{p}$-value $=0.0103$ ) Variations of TT levels had a higher impact on predicting high-grade disease $(\mathrm{GS} \geq 7)$ among Black men compared to White men $(\mathrm{p}=0.02)$ (Figure 1). We also observed that obese patients had a higher prevalence of hypogonadism compared to men with normal BMI ( $\mathrm{p}$-value $<0.001$ ).

\section{Discussion}

We present the results of a retrospective assessment of the association between serum testosterone levels and PCa grade in a large Latin American cohort. In our results, low TT was an independent predictor for high-grade PCa among patients undergoing RP. This effect was signifi- 
TABLE 1 Characteristics of patients.

\section{Variable}

BMI (Mean \pm SD)

Age (Mean \pm SD)

Testosterone (Mean \pm SD)

PSA (Median, IQR)

\section{Results}

$26.8 \pm 4.3$

$63.6 \pm 6.6$

$380.0 \pm 183.2$

$13.0(6.1-14.7)$

BMI: body mass index; PSA: prostate-specific antigen; IQR: interquartile range; SD: standard deviation.

TABLE 2 Clinicopathological characteristics of the 423 patients included in the study.

\begin{tabular}{|c|c|c|}
\hline Variables & Groups & $N(\%)$ \\
\hline \multirow[t]{4}{*}{ Race } & Asian & $3(0.7 \%)$ \\
\hline & Caucasian & $360(86.3 \%)$ \\
\hline & Black & $20(4.8 \%)$ \\
\hline & Pardo (Brown multiracial) & $34(8.2 \%)$ \\
\hline \multirow[t]{2}{*}{ Pathological stage } & $<\mathrm{T} 3 \mathrm{a}$ & $291(71.1 \%)$ \\
\hline & $\geq \mathrm{T} 3 \mathrm{a}$ & $118(28.9 \%)$ \\
\hline \multirow[t]{2}{*}{ Positive lymph nodes } & Absent & $211(95.0 \%)$ \\
\hline & Present & $11(5.0 \%)$ \\
\hline \multirow[t]{2}{*}{ Gleason score } & $<7$ & $107(25.4 \%)$ \\
\hline & $\geq 7$ & $314(74.6 \%)$ \\
\hline \multirow[t]{4}{*}{ Age-adjusted Charlson comorbidity score } & 0 & $15(3.7 \%)$ \\
\hline & 1 & $90(22.2 \%)$ \\
\hline & 2 & $204(50.4 \%)$ \\
\hline & $\geq 3$ & $96(23.7 \%)$ \\
\hline \multirow[t]{2}{*}{ PSA } & $<10$ & $197(53.4 \%)$ \\
\hline & $\geq 10$ & $172(46.6 \%)$ \\
\hline \multirow[t]{2}{*}{ Testosterone levels (threshold 1) } & $<300$ & $160(37.8 \%)$ \\
\hline & $\geq 300$ & $263(62.2 \%)$ \\
\hline \multirow[t]{2}{*}{ Testosterone levels (threshold 2) } & $<250$ & $101(23.9 \%)$ \\
\hline & $\geq 250$ & $322(76.1 \%)$ \\
\hline \multirow[t]{3}{*}{ Risk stratification (NCCN) } & Low & $50(14.4 \%)$ \\
\hline & Intermediate & $213(61.4 \%)$ \\
\hline & High & $84(24.2 \%)$ \\
\hline
\end{tabular}

PSA: prostate-specific antigen.

TABLE 3 Comparison of pathological characteristics of patients with hypogonadism vs. eugonadism (classified using the $300 \mathrm{ng} / \mathrm{dL}$ threshold).

\begin{tabular}{|c|c|c|c|c|}
\hline \multicolumn{5}{|c|}{ Testosterone levels } \\
\hline Variables & Groups & $<300$ & $\geq 300$ & p-value \\
\hline \multirow[t]{2}{*}{ Pathological stage } & $<\mathrm{T} 3 \mathrm{a}$ & $114(73.1 \%)$ & $177(70.0 \%)$ & 0.5744 \\
\hline & $\geq \mathrm{T} 3 \mathrm{a}$ & $42(26.9 \%)$ & $76(30.0 \%)$ & \\
\hline \multirow[t]{2}{*}{ Positive lymph nodes } & Absent & $86(93.5 \%)$ & $125(96.2 \%)$ & 0.5319 \\
\hline & Present & $6(6.5 \%)$ & $5(3.8 \%)$ & \\
\hline \multirow[t]{2}{*}{ Gleason score } & $<7$ & $30(18.9 \%)$ & $77(29.4 \%)$ & 0.0207 \\
\hline & $\geq 7$ & $129(81.1 \%)$ & $185(70.6 \%)$ & \\
\hline \multirow[t]{2}{*}{ Risk stratification (NCCN) } & High/Inter & $113(88.3 \%)$ & $184(84.0 \%)$ & 0.3422 \\
\hline & Low & $15(11.7 \%)$ & $35(16.0 \%)$ & \\
\hline
\end{tabular}


TABLE 4 Comparison of characteristics of patients with hypogonadism vs. eugonadism (classified using the $250 \mathrm{ng} / \mathrm{dL}$ threshold). Testosterone levels

\begin{tabular}{|c|c|c|c|c|}
\hline Variables & Groups & $<250$ & $\geq 250$ & p-value \\
\hline \multirow[t]{2}{*}{ Pathological stage } & $<\mathrm{T} 3 \mathrm{a}$ & $66(68.0 \%)$ & $225(72.1 \%)$ & 0.4438 \\
\hline & $\geq \mathrm{T} 3 \mathrm{a}$ & $31(32.0 \%)$ & $87(27.9 \%)$ & \\
\hline \multirow[t]{2}{*}{ Positive lymph nodes } & Absent & $54(90.0 \%)$ & $157(96.9 \%)$ & 0.0733 \\
\hline & Present & $6(10.0 \%)$ & $5(3.1 \%)$ & \\
\hline \multirow[t]{2}{*}{ Gleason score } & $<7$ & $16(16.0 \%)$ & $91(28.3 \%)$ & 0.0126 \\
\hline & $\geq 7$ & $84(84.0 \%)$ & $230(71.7 \%)$ & \\
\hline \multirow[t]{2}{*}{ Risk stratification (NCCN) } & High/Inter & $69(88.5 \%)$ & $228(84.8 \%)$ & 0.4688 \\
\hline & Low & $9(11.5 \%)$ & $41(15.2 \%)$ & \\
\hline
\end{tabular}

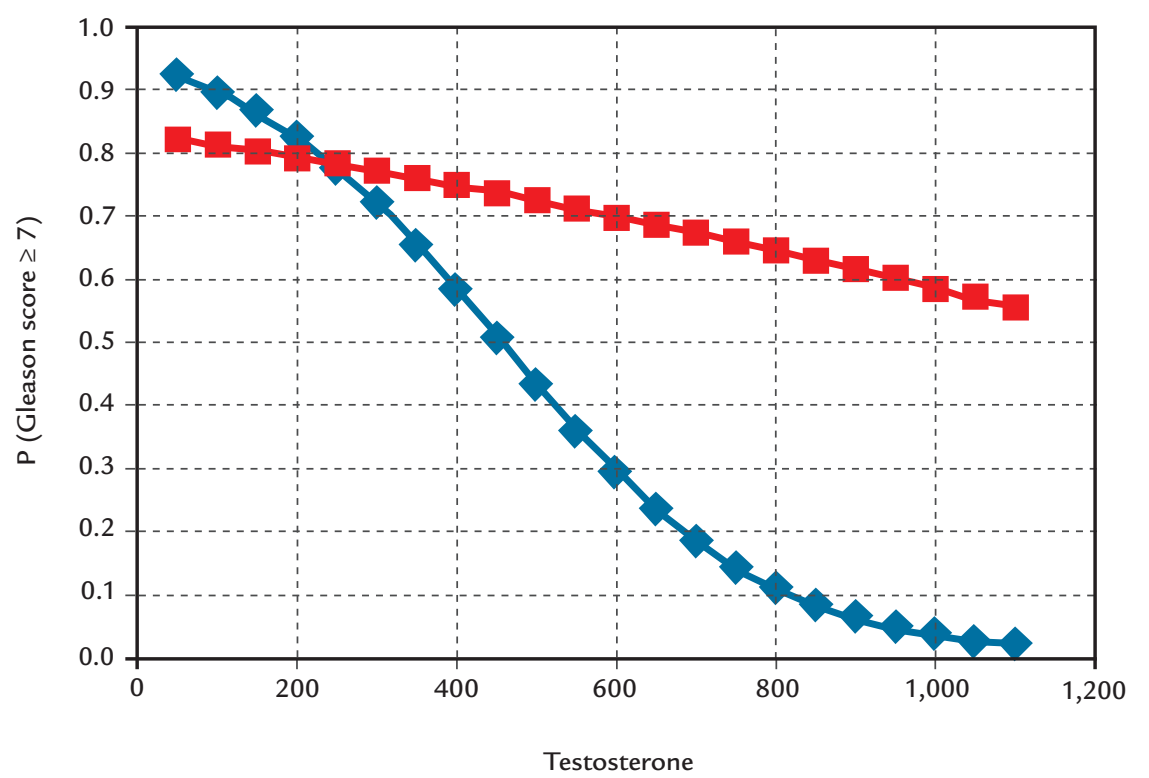

Black

Caucasian

FIGURE 1 Interaction between TT levels and race in predicting the risk of high-grade PCa. Among Black individuals, hypogonadism had a stronger effect in predicting high-grade disease $(p=0.038)$, although there was a similar trend among Caucasians $(p=0.06)$. Both groups differed significantly in this behavior $(p=0.02)$.

cantly more pronounced among Black men, who also had higher incidence of hypogonadism. These results may reveal an underlying mechanism for higher-grade $\mathrm{PCa}$ found in Black race, and may also partly explain inconsistencies between previous investigations regarding the association between TT and PCa grade.

Although the response of metastatic PCa to androgen deprivation therapy is well established, it is still controversial whether androgens are responsible for the initiation of PCa. Age, one of the strongest risk factors for PCa, is knowingly associated with a gradual decline in testosterone levels. However, that does not preclude a pathogenic role for androgens, given the long preclinical phase of PCa. Yet, multiple population-based studies have failed to show an association of circulating testosterone, dihydrotestosterone (DHT) or other sex steroids with PCa risk. ${ }^{14,15}$

The Endogenous Hormones and Prostate Cancer Collaborative Group reviewed 18 prospective studies and failed to demonstrate an association between endogenous testosterone and PCa risk. Also, testosterone levels did not correlate to PCa aggressiveness. ${ }^{5}$ Similarly, many studies have shown that testosterone replacement therapy 
(TRT) promotes limited changes in PSA levels when men with hypogonadism are treated to normalize testosterone.

Morgentaler and Traish proposed a saturation model theory of testosterone and the prostate. ${ }^{16}$ According to this theory, $\mathrm{PCa}$ is testosterone-sensitive at low testosterone levels, but after androgen receptors are fully occupied, further testosterone increments have modest or no effect on the prostate or PCa dynamics. This hypothesis is supported by studies in men on TRT showing modest or no PSA increase after initiating testosterone injections, as well as no increased risk for cancer. ${ }^{17,18}$

There are many reports on the role of testosterone in predicting high-risk disease, although with contrasting results and employing different methodological standards and outcomes. Schatzl et al. reported on a higher risk for high-grade Gleason scores in men with low serum testosterone among patients diagnosed with PCA. ${ }^{19}$ Similarly, Pichon et al. showed, among subjects undergoing RP for PCa, that lower testosterone levels were associated with higher-grade PCa and with increased risk of GS upgrading from prostate biopsy to specimens from surgery. ${ }^{20}$ Park et al. ${ }^{9}$ demonstrated a correlation between hypogonadism and unfavorable outcomes in prostatic biopsies, such as increased incidence of $G S \geq 8$. Several studies, despite adopting different thresholds for the definition of hypogonadism, have confirmed an association between low testosterone levels and adverse characteristics and outcomes for $\mathrm{PCa}$, including higher Gleason score, ${ }^{21,22}$ higher pathological stage ${ }^{10,22}$ and increased risk for disease progression. ${ }^{23}$

However, a number of investigations failed to show an association between low serum testosterone levels and high-risk characteristics of PCa specimens. Salonia et al. ${ }^{12}$ found an association between androgens and higher risk PCa that was not proven to be independent on multivariate analysis. Other studies showed no association, ${ }^{12,24}$ while Porcaro et al. suggest a direct relation between testosterone levels and Gleason score, a result that opposes the findings described previously. ${ }^{25}$

In our study, we evaluated 423 patients and tested two thresholds, 250 and $300 \mathrm{ng} / \mathrm{dL}$, for the definition of hypogonadism. We used pathological findings from RP specimens in order to most accurately reflect tumor characteristics. In keeping with other reports, we found a significant and independent correlation between low TT levels (threshold 1 and threshold 2) and high-grade disease $(\mathrm{GS} \geq 7$ ). We also analyzed the correlation between preoperative hypogonadism and pathological stage and the presence of lymph nodes involved by the disease. This relationship proved to be non-significant, although there was a trend towards higher stage $(\geq \mathrm{T} 3 \mathrm{a})$ on threshold 2 and positive lymph nodes in both thresholds.

In our cohort, low TT levels were also significantly associated with race and BMI characteristics. This resulted in a significant interaction between these variables and the outcome of higher grade PCa. We hypothesize that inconsistencies between previous studies on this subject may be due to demographic variability between cohorts, owing to the effect that interaction with race may produce. We also hypothesize that low serum testosterone may be one of the mechanisms mediating previously reported associations between demographic groups and increased risk for high-grade PCa.

Nunzio et al., in a prospective multicenter study, evaluated the association between abdominal obesity, PCa diagnosis and grade in 668 patients undergoing prostate biopsy. PCa was detected in 246 patients (38\%), of whom 110 had a higher-grade cancer (GS $\geq 7$ ). Logistic regression showed that BMI and waist circumference were significant predictors of high-grade PCa. Furthermore, obesity with central adiposity was significantly associated with high-grade disease. ${ }^{26}$

Black men have a $67 \%$ higher incidence of PCa compared to Caucasians. ${ }^{27}$ While population-level studies have consistently shown that the incidence and mortality burden is highest among Black men, it remained unclear whether this can be explained by inadequate access to medical care. ${ }^{28}$ Gaines et al., in a population-based study involving 887 men, evaluated the association between race and low- and high-grade PCa in men undergoing initial prostate biopsy in an equal access medical center. Of the 887 men, 499 had PCa on biopsy (56.3\%). Black men were significantly more likely to have PCa on biopsy than White men $61,9 \%$ vs. $50.9 \%$ ( $\mathrm{p} \leq 0.001)$. In multivariate analyses, Black race was significantly predictive of high-grade. ${ }^{29}$

In our study, on multivariate analysis adjusted for BMI and race, only low levels of TT and advanced age had a significant impact in predicting GS $\geq 7$. Low TT was associated with increased BMI, and hypogonadism was a stronger predictor of high-grade PCa among Black individuals. Based on these observations, we hypothesize that low serum testosterone may be an underlying mechanism involved in higher-grade PCa found in both obese and Black men in previous reports. These results should be further confirmed in larger populations and tested on molecular level.

It has been hypothesized that patients with low TT would have lower PSA and for this reason would take longer to be diagnosed with PCa, hence explaining the 
association between low TT and high-grade PCa. However, our findings confront this hypothesis, as changes in serum testosterone did not correlate with changes in PSA. This is in consonance with previous investigations. ${ }^{9}$ Furthermore, low TT predicted high-grade PCa independently of age at diagnosis, which also opposes this conjecture. Rather, we believe that, according to the Saturation Model, patients with hypogonadism do not reach levels of testosterone necessary for physiological proliferation of the epithelium, leading to a greater risk of abnormal proliferation and differentiation, resulting in greater risk for high-grade cancer.

Our results should be interpreted in the context of a number of limitations. The retrospective nature of the study, the lack of a standardized protocol for testosterone measurement and the selection of patients from a high-volume cancer center imply biases for epidemiological observations. Many patients were not included in the study because their TT measurement had been performed prior to 6 months from surgery, introducing a bias that excluded patients who waited longer until radical prostatectomy. Furthermore, our observations on the effect of low TT in Black men are based on a limited sample. However, we believe that our study provides meaningful insight into associations between testosterone levels, prostate cancer grade and race interactions, and should warrant further prospective investigations.

\section{Conclusion}

According to our findings, hypogonadism is an independent risk factor for developing higher GS in localized PCa. Low levels of TT might be related to the carcinogenesis of higher grade cancer and is a potential marker of prognosis in PCa. In our sample, low TT level was a stronger predictor of high-grade PCa in Black men compared to White men, which could partly explain the behavior of the disease in this ethnic group and should warrant further investigation.

\section{Resumo}

Baixa testosterona sérica é prognóstica de doença de alto grau em pacientes com câncer de próstata

Objetivo: Avaliar a relação entre testosterona sérica total (TT) e grau do câncer de próstata (CP) e o efeito da raça e de características demográficas sobre essa associação.

Método: Foram analisados 695 pacientes submetidos a prostatectomia radical (PR), dos quais 423 tinham medidas dos níveis séricos de TT. Os pacientes foram classificados como portadores de hipogonadismo ou eugonadismo com base em dois limites de testosterona: limite $1(300 \mathrm{ng} / \mathrm{dL})$ e limite $2(250 \mathrm{ng} / \mathrm{dL})$. Avaliou-se a relação entre nível de TT e escore Gleason (GS) $\geq 7$ em amostras de PR. Os resultados foram avaliados por análises univariada e multivariada, com ajuste para raça e outros fatores prognósticos demográficos.

Resultados: Do total de 423 pacientes, $37,8 \%$ apresentavam hipogonadismo com base no limite 1 , e $23,9 \%$ com base no limite 2. Os pacientes com hipogonadismo, independentemente do limite de referência, tiveram uma chance maior de GS $\geq 7$ (OR 1,79, $\mathrm{p}=0,02$ e OR 2,08, $\mathrm{p}=0,012$, respectivamente). $\mathrm{Na}$ análise multivariada, após ajuste para idade, TT, índice de massa corporal (IMC) e raça, baixo TT $(\mathrm{p}=0,023)$ e idade $(\mathrm{p}=0,002)$ foram considerados fatores de risco independentes para GS $\geq 7$. Entre os indivíduos negros, baixo TT sérico foi mais preditivo de doença de alto grau em comparação com os brancos $(\mathrm{p}=0,02)$. Conclusão: $O$ hipogonadismo é independentemente associado a escores mais altos de GS no CP localizado. O efeito dessa associação é significativamente mais pronunciado entre homens negros, o que poderia explicar, em parte, as características agressivas do CP observadas nessa população.

Palavras-chave: câncer de próstata, hipogonadismo, testosterona.

\section{References}

1. Ferlay J, Bray F, Pisani P, Parkin DM. GLOBOCAN 2002. Cancer Incidence, Mortality and Prevalence Worldwide, Version 2.0. Lyon: IARC Press; 2004.

2. Bostwick DG, Burke HB, Djakiew D, Euling S, Ho SM, Landolph J, et al. Human prostate cancer risk factors. Cancer. 2004; 101(10 Suppl):2371-490.

3. Huggins C, Stevens RE Jr, Hodges CV. Studies on prostate cancer. II. The effect of castration on advanced carcinoma of the prostate gland. Arch Surg. 1941; 43(2):209-23.

4. Morgentaler A. Testosterone replacement therapy and prostate cancer. Urol Clin N Am. 2007; 34(4):555-63, vii.

5. Endogenous Hormones and Prostate Cancer Collaborative Group, Roddam AW, Allen NE, Appleby P, Key TJ. Endogenous sex hormones and prostate cancer: a collaborative analysis of 18 prospective studies. J Natl Cancer Inst. 2008; 100(3):170-83.

6. Isbarn H, Pinthus JH, Marks LS, Montorsi F, Morales A, Morgentaler A, et al. Testosterone and prostate cancer: revisiting old paradigms. Eur Urol. 2009; 56(1):48-56.

7. Morgentaler A. Turning conventional wisdom upside-down: low serum testosterone and high-risk prostate cancer. Cancer. 2011; 117(17):3885-8.

8. Morgentaler A, Bruning CO 3rd, DeWolf WC. Occult prostate cancer in men with low serum testosterone levels. JAMA. 1996; 276(23):1904-6.

9. Park J, Cho SY, Jeong S, Lee SB, Son H, Jeong H. Low testosterone level is an independent risk factor for high-grade prostate cancer detection at biopsy. BJU Int. 2016; 118(2):230-5.

10. Isom-Batz G, Bianco FJ, Kattan MW, Mulhall JP, Lilja H, Eastham JA. Testosterone as a predictor of pathological stage in clinically localized prostate cancer. J Urol. 2005; 173(6):1935-7.

11. Imamoto T, Suzuki H, Fukasawa S, Shimbo M, Inahara M, Komiya A, et al Pretreatment serum testosterone level as a predictive factor of pathological stage in localized prostate cancer patients treated with radical prostatectomy. Eur Urol. 2005; 47(3):308-12. 
12. Salonia A, Gallina A, Briganti A, Abdollah F, Suardi N, Capitanio U, et al. Preoperative hypogonadism is not an independent predictor of high-risk disease in patients undergoing radical prostatectomy. Cancer. 2011; 117(17):3953-62.

13. Shin BS, Hwang EC, Im CM, Kim SO, Jung SI, Kang TW, et al. Is a decreased serum testosterone level a risk factor for prostate cancer? A cohort study of Korean men. Korean J Urol. 2010; 51(12):819-23.

14. Grossmann M, Cheung AS, Zajac JD. Androgens and prostate cancer; pathogenesis and deprivation therapy. Best Pract Res Clin Endocrinol Metab. 2013; 27(4):603-16.

15. Grossman M, Wittert G. Androgens, diabetes and prostate cancer. Endocr Relat Cancer. 2012; 19(5):F47-62.

16. Morgentaler A, Traish AM. Shifting the paradigm of testosterone and prostate cancer: the saturation model and the limits of androgen-dependent growth. Eur Urol. 2009; 55(2):310-20.

17. Coward RM, Simhan J, Carson CC 3rd. Prostate-specific antigen changes and prostate cancer in hypogonadal men treated with testosterone replacement therapy. BJU Int. 2009, 103(9):1179-83.

18. Rhoden EL, Morgentaler A. Testosterone replacement therapy in hypogonadal men at high risk for prostate cancer: results of 1 year of treatment in men with prostatic intraepithelial neoplasia. J Urol. 2003; 170 (6 Pt 1):2348-51.

19. Schatzl G, Madersbacher S, Thurridl T, Waldmüller J, Kramer G, Haitel A, et al. High-grade prostate cancer is associated with low serum testosterone levels. Prostate. 2001; 47(1):52-8.

20. Pichon A, Neuzillet Y, Botto H, Raynaud JP, Radulescu C, Molinié V, et al. Preoperative low serum testosterone is associated with high-grade prostate cancer and an increased Gleason score upgrading. Prostate Cancer Prostatic Dis. 2015; 18(4):382-7.

21. Dai B, Qu Y, Kong Y, Ye D, Yao X, Zhang S, et al. Low pretreatment serum total testosterone is associated with a high incidence of Gleason score 8-10 disease in prostatectomy specimens: data from ethnic Chinese patients with localized prostate cancer. BJU Int. 2012; 110(11 Pt B):E667-72.

22. Xylinas E, Ploussard G, Durand X, Fabre A, Salomon L, Allory Y, et al. Low pretreatment total testosterone $(<3 \mathrm{ng} / \mathrm{mL})$ predicts extraprostatic disease in prostatectomy specimens from patients with preoperative localized prostate cancer. BJU Int. 2011; 107(9):1400-3.

23. García-Cruz E, Piqueras M, Huguet J, Peri L, Izquierdo L, Musquera M, et al. Low testosterone levels are related to poor prognosis factors in men with prostate cancer prior to treatment. BJU Int. 2012; 110(11 Pt B):E541-6.

24. Morote J, Ramirez C, Gómez E, Planas J, Raventós CX, de Torres IM, et al. The relationship between total and free serum testosterone and the risk of prostate cancer and tumour aggressiveness. BJU Int. 2009; 104(4):486-9.

25. Porcaro AB, Petrozziello A, Ghimenton C, Migliorini F, Sava T, Caruso $B$, et al. Associations of pretreatment serum total testosterone measurements with pathology-detected Gleason score cancer. Urol Int. 2014; 93(3):269-78.

26. De Nunzio C, Albisinni S, Freedland SJ, Miano L, Cindolo L, Finazzi Agrò $\mathrm{E}$, et al. Abdominal obesity as risk factor for prostate cancer diagnosis and high grade disease: a prospective multicenter Italian cohort study. Urol Oncol. 2013; 31(7):997-1002.

27. Howlader N, Noone AM, Krapcho M, Garshell J, Neyman N, Altekruse SF, et al., editors. SEER Cancer Statistics Review, 1975-2010. National Cancer Institute. Bethesda. 2013.

28. Powell IJ. Epidemiology and pathophysiology of prostate cancer in AfricanAmerican men. J Urol. 2007; 177(2):444-9.

29. Gaines AR, Turner EL, Moorman PG, Freedland SJ, Keto CJ, McPhail ME, et al. The association between race and prostate cancer risk on initial biopsy in an equal access, multiethinic cohort. Cancer Causes Control. 2014; 25(8):1029-35 